\title{
Archivo Eduardo Torroja. La Sede del itcc (1949-1953) Inéditos anteproyectos previos a su construcción
}

\author{
Eduardo Torroja archives \\ The itcc headquarters (1949-1953) \\ Unpublished project briefs
}

V. Azorín $^{(*)}$, P. Cassinello ${ }^{(* *)}$, J. Monjo $^{(* *)}$

RESUMEN

El contenido de este artículo representa el eslabón que falta en la historia publicada por la revista Informes de la Construcción sobre el proyecto y construcción de la nueva sede del Instituto, que fue el hábitat de investigación más innovador jamás construido por la Modernidad. Su difusión completa y cierra esta historia, a la vez que potencia el mensaje que Eduardo Torroja quiso transmitir agrupando los artículos que relatan esta historia, bajo un mismo título común; "El Instituto es Así", seguramente porque durante mucho tiempo (1949-1953), defendió que no podía ser de otra manera.

Este trabajo ha sido posible gracias a la ayuda concedida por el Ministerio de Ciencia e Innovación a través del proyecto de I+D+i (Ref.: HUM2007-65543) titulado: El fondo documental generado por Eduardo Torroja en el IETCC como memoria histórica en el proceso de transferencia tecnológica en Ciencias de la Construcción.

108.15

Palabras clave: Eduardo Torroja, Archivo, Investigación, Construcción, Arquitectura.

\section{SUMMARY}

The content of the present article constitutes the missing link in the history published in Informes de la Construcción on the design and construction of the Institute's new headquarters, the most innovative habitat for research ever built by the modern movement. Its publication completes and concludes that record, while highlighting the message that Eduardo Torroja intended to transmit when he grouped the articles that narrated its history under a common title: El Instituto es así (Making the Institute what it is), very likely because for many years (1949-1953) he contended that it could not have been "made" otherwise.

A Ministry of Science and Innovation $1+D+i$ project (ref.: HUM2007-65543) entitled: EI fondo documental generado por Eduardo Torroja en el IETCC como memoria histórica en el proceso de transferencia tecnológica en Ciencias de la Construcción (History of the body of documents generated by Eduardo Torroja in the IETCC with a view to construction science technology transfer).

Keywords: Eduardo Torroja, Archive, Investigation, Construction, Architecture.

(*) Instituto de Ciencias de la Construcción Eduardo Torroja (CSIC). Madrid (España)

(*) ETSA, Universidad Politécnica de Madrid. Madrid (España)

Fecha de recepción: 10-03-11

Persona de contacto/Corresponding author: vazorin@ietcc.csic.es (V. Azorín) 


\section{INTRODUCCIÓN}

El Instituto de Ciencias de la Construcción "Eduardo Torroja" del CSIC (IETCC), es uno de los mejores centros de tecnológicos y de investigación en construcción en España debido a la importancia de los logros conseguidos y que forman parte de la Historia de la Construcción Contemporánea. La actividad desarrollada en el Instituto desde sus inicios, ha quedado reflejada de modo evidente en su archivo, dentro del cual destaca, por su valor histórico, el "corpus" generado por su fundador Eduardo Torroja siendo director del mismo.

Conscientes de este hecho, científicos del Instituto, en el año 2007 solicitaron al Ministerio de Ciencia e Innovación a través de un Proyecto de $\mathrm{I}+\mathrm{D}+\mathrm{i}$, una ayuda para poder abordar el inicio de su organización, clasificación y análisis de la documentación existente en este valioso archivo. Este proyecto denominado: El fondo documental generado por Eduardo Torroja en el IETCC como memoria histórica en el proceso de transferencia tecnológica en Ciencias de la Construcción (Ref.: HUM2007-65543) fue atendido favorablemente y sus resultados han permitido descubrir, catalogar y analizar, inéditos documentos, que permiten reconstruir algunas lagunas del conocimiento de esta relevante Historia, poniendo de manifiesto, una vez más, el ingenio de esta figura mítica de la ingeniería española.

Tras la organización del archivo, se constató la existencia de documentos personales de Eduardo Torroja, documentación de carácter administrativo, de carácter científico, publicaciones, conferencias, seminarios, jornadas, visitas, participación en asociaciones nacionales e internacionales, etc. Entre toda esta documentación destaca la relativa a la construcción del edificio "Costillares", la sede del Instituto, que Eduardo Torroja inauguró en el año 1953. El Archivo cuenta con más de 500 planos originales, la mayoría corresponden al edificio del Instituto Técnico de la Construcción y del Cemento proyectado en 1951, pero además se han encontrado una serie de anteproyectos inéditos, que nunca fueron construidos y que hasta ahora no habían sido analizados ni difundidos. De estos anteproyectos se conservan planos originales realizados a mano, a tinta, a lápiz, y algunos con tintas de colores en papel vegetal. También existen planos realizados en papel poliéster, así como algunos bocetos y copias y papel azográfico, así como parte de sus memorias técnicas.

Dado que Eduardo Torroja difundió, la innovadora construcción de la nueva y actual sede del Instituto, a través de la revista Infor- mes de la Construcción (1, 2, 3, 4, 5, 6 y 7) hemos querido que la primacía de la difusión de la parte documental que completa esta historia, sea también difundida por su revista, como el eslabón que falta para entender la especial estrategia seguida por Eduardo Torroja para llegar a construir el más innovador hábitat de la investigación del sector, que la Modernidad construyó en toda su Historia.

\section{LA NUEVA SEDE DEL ITCC 1949-1953}

En el año 1949, Eduardo Torroja, dado el desarrollo alcanzado por el Instituto Técnico de la Construcción y del Cemento (itcc), comunica al Patronato Juan de la Cierva del CSIC la imperiosa necesidad de construir una nueva sede para el Instituto. El CSIC le facilita los planos y documentación necesaria para que estudie la posibilidad de construir el nuevo itcc en un solar de su propiedad, que estaba ubicado en la "Colina de los Chopos", junto a otros centros también pertenecientes al Consejo Superior de Investigaciones Científicas.

"Dado el desarrollo actual del Instituto y el estado avanzado en que se encuentran ya las investigaciones emprendidas, se requiere inexorablemente, y en un plazo breve, contar con laboratorios y naves de experimentación adecuadas para ellas. Como es sabido, éstas investigaciones abarcan todo el campo de la construcción, desde la fabricación de sus materiales al estudio de las modernas técnicas constructivas." (Informe E. Torroja, 1949: AHT/OI/A/001)

Eduardo Torroja, no solo se ocupó personalmente de la dirección, organización y desarrollo del itcc, convirtiéndolo en sede nacional e internacional de nuevas asociaciones que fundó y/o presidió hasta su muerte en 1961, sino que tal y como pone de manifiesto el presente análisis, puso un especial e incansable empeño en encontrar un solar adecuado para poder proyectar y construir un hábitat para su nueva, ambiciosa y revolucionaria idea. Un hábitat sin el cual no hubiera sido posible realizar la relevante e internacional labor llevada a cabo (Figura 1).

Se trataba de construir un centro de investigación que no debía limitarse al desarrollo de la investigación en sí misma, sino que debía también realizar la necesaria difusión y enseñanza de todas las aplicaciones prácticas resultantes, asegurándose de que realmente eran puestas al servicio de la sociedad. La inseparable unión de estas tres actividades, fue entendida por Eduardo Torroja como único medio para impulsar el progreso, no solo de la entonces deprimida España de postguerra, sino como modelo atemporal para todo el contexto internacional de la construcción. 


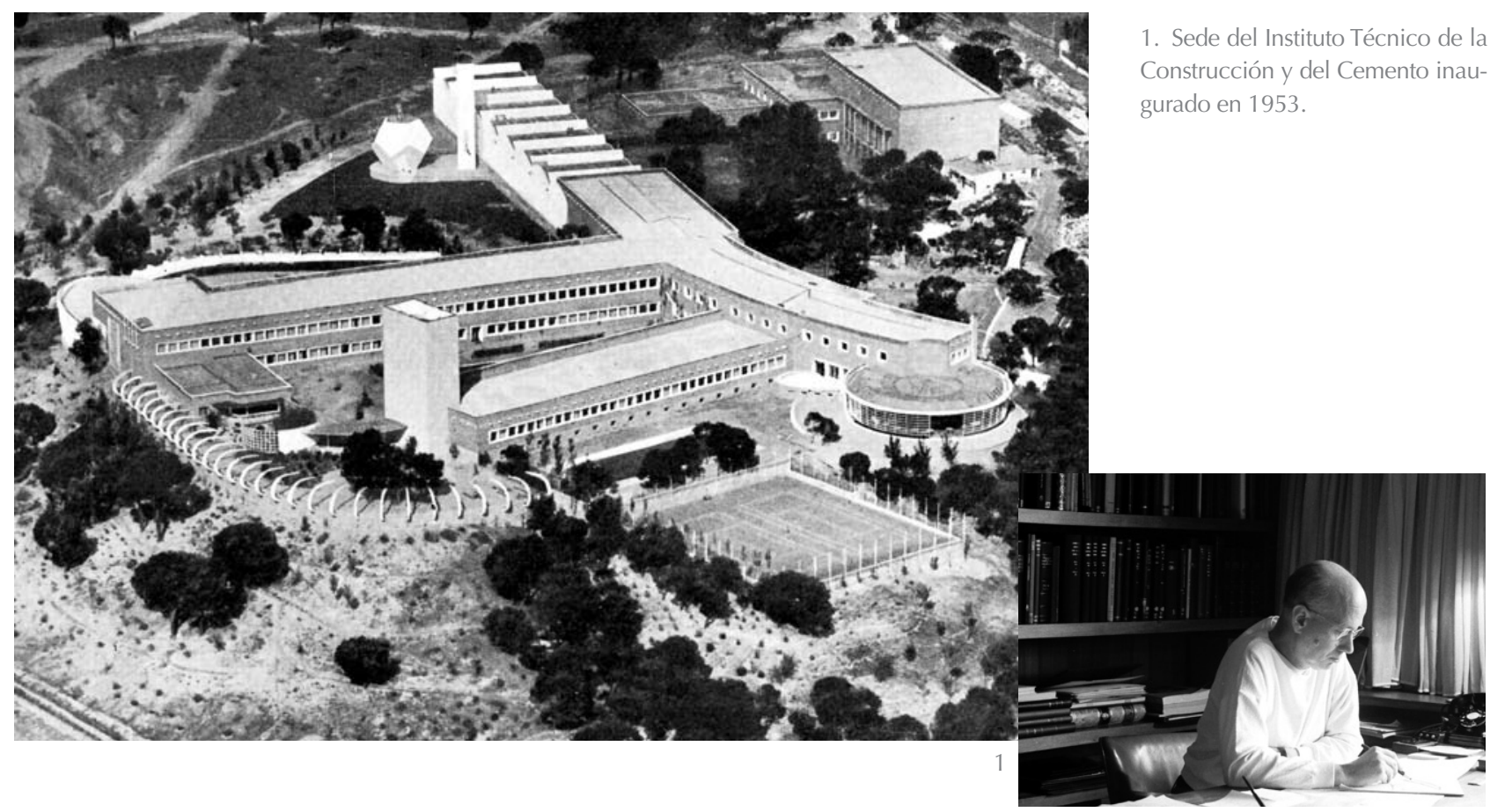

Por esta razón, Eduardo Torroja, durante más de tres años (1949-1953), de forma incansable y audaz, centró gran parte de sus esfuerzos en conseguir encontrar el lugar y los medios necesarios para construir una nueva sede para el itcc (Instituto Técnico de la Construcción y del Cemento). Es un hecho ya constatado que la construcción de este Instituto cambió el rumbo de la Historia de la investigación española en el campo de la construcción civil y arquitectónica, y con ella, sin duda, la del desarrollo de la deprimida España.

Al poco tiempo de recibir la documentación del solar del CSIC, el 21 de enero de 1950, Eduardo Torroja presentó un "anteproyecto" para la nueva sede del itcc, desarrollado en el solar delimitado por las calles; Serrano, Gustavo Fernández Balbuena y Joaquín Costa, que era ya propiedad del Patronato Juan de la Cierva. (IETcc / Archivo Torroja - D1). En este anteproyecto el Instituto, dirigido por Eduardo Torroja, desarrolla tres soluciones diferentes, que responden a la optimización de la ocupación del suelo, no solo en función de sus propias necesidades, sino también de las previsiones del Patronato Juan de la Cierva, que al parecer, tenía reservado parte de dicho solar para la futura construcción de la sede del Instituto de Hierro, así como de sus propias oficinas.

En la solución A, considerada por el itcc como la mejor para sus necesidades, se plantea la posibilidad de que el Patronato destine la totalidad del solar a la nueva sede del Instituto, y que incluso adquiera los terrenos de una vaquería que enton- ces ocupaba una pequeña parte del solar (IETcc / Archivo Torroja - D1).

En la memoria presentada se enfatiza el hecho de que ésta es la mejor solución para poder cubrir la demanda de sus necesidades, no solo en lo que se refiere a sus necesidades de superficie construida para oficinas, talleres, naves de ensayos, laboratorios, etc..., sino también para poder contar con suficiente espacio libre en el solar, destinada a desarrollar construcciones experimentales y acopio de materiales.

Ante la posibilidad de que el Patronato "Juan de la Cierva" no aceptara destinar el solar únicamente a la nueva sede del itcc, la dirección del centro presenta otras dos soluciones. Una solución B, en la cual se contempla la posibilidad de construir, en el mismo solar, el edificio del Patronato, con fachada a la calle Serrano, junto con los edificios del Instituto ocupando las fachadas de Joaquín Costa y de Gustavo Fernández Balbuena.

También presenta una solución C, para el caso en el que el Patronato mantenga su intención de construir en el mismo solar, el Instituto del Hierro además de sus propias oficinas y los edificios del Instituto Técnico de la Construcción y del Cemento. Aunque esta última solución $\mathrm{C}$, es la que el itcc considera la peor, por restarle mucho espacio a sus instalaciones, es sin embargo la que desarrolla a nivel, ya no de anteproyecto, sino casi de proyecto de ejecución, dado que es la que responde a las intenciones del Patronato, y que por consiguiente, el Instituto debió considerar, como la más probable de ser aceptada en aquellos momentos. 
2. Anteproyecto no construido. Solución C. Plano de situación.
En base a los planos encontrados recientemente en el archivo del IETcc, esta solución C consistía, en efecto, en la propuesta de ocupar el solar con diferentes edificaciones destinadas a tres instituciones; El Patronato Juan de la Cierva, y dos de sus Institutos, el del Hierro y el itcc. El primero ocuparía un solo edificio con fachada a la calle Serrano, el segundo un edificio con fachada a la calle de Joaquín Costa y el itcc, ocuparía un conjunto de 4 edificios, el principal con facha a la calle Gustavo Fernández Balbuena, y los otros tres estarían ubicados en el interior del solar. (Figura 2. Anteproyecto no construido. IETcc/Archivo Torroja - D2).

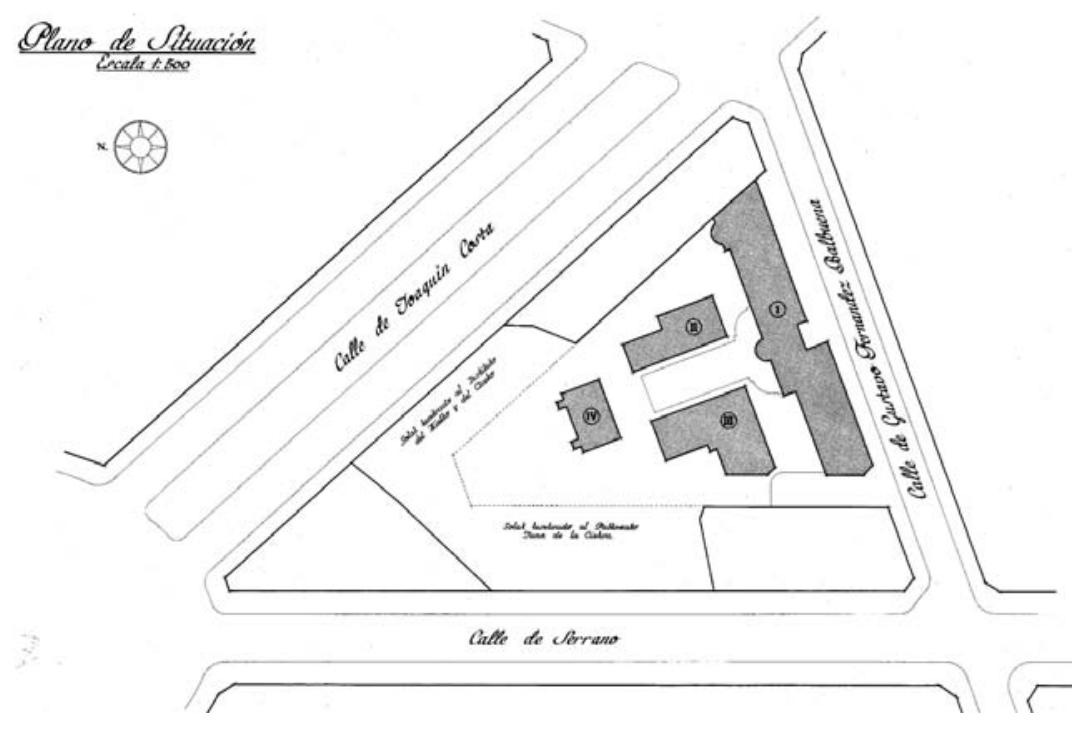

2

En la memoria explicativa de estas tres soluciones, el itcc resalta el hecho de que la solución C, cuenta con muchos defectos. En primer lugar señala que esta solución, demanda la necesidad de que los edificios cuenten con mayor número de plantas para poder albergar el mismo programa, hecho que derivaba en un sustancial incremento de coste, ya que los forjados deberían ser dimensionados con una gran resistencia para poder desarrollar sobre ellos actividades de ensayos físicos y pruebas experimentales que así lo requieren en base, no solo al gran peso propio de algunas maquinarias y piezas a ensayar, sino a las cargas dinámicas producidas durante el proceso de ensayo. Por otra parte, comentan que el exceso de edificios construidos en el solar, así como la extrema cercanía resultante entre todos ellos, desembocaba en una gran escasez de espacio libre, hecho que impedía al itcc poder contar con el espacio exterior libre necesario para realizar construcciones experimentales de módulos de viviendas, acopio de materiales o curado de grandes piezas prefabricadas. (Archivo Torroja-D 1).
"De todos modos, si no hubiera más remedio, podría aceptarse esta solución, pero nunca quedaría orgánicamente tan bién como las anteriores ( $A$ y B), ni podría rebajarse al máximo el coste como en estas otras, que se pueden desarrollar mejor en una planta." (E. Torroja: Memoria del Anteproyecto presentado al CSIC. 1950. Archivo Torroja-D 1).

En un principio nos resultaba difícil entender la razón que motivó a Eduardo Torroja a que se realizara, bajo su directa supervisión, este denominado "anteproyecto" de la solución C, que sin embargo fue desarrollado a nivel de proyecto de ejecución, presentando planos de cimentación, estructura, instalaciones, ...y que finalmente no fue construido.

Pero el análisis, no solo de los planos sino de la memoria presentada al CSIC y firmada por Eduardo Torroja, deja patente que este esfuerzo tenía un claro y audaz objetivo; el de poder demostrar al Consejo Superior de Investigaciones Científicas que se habían estudiado muy a fondo todas las posibilidades del solar ofrecido, pero que ninguna de las posibles soluciones era la adecuada para la nueva sede del itcc. Parece claro que Eduardo Torroja quería demostrar de forma rotunda, que las actividades de investigación que se estaban realizando en el Instituto que él dirigía y las que quería ampliar en un futuro inmediato, demandaban una nueva sede mucho más ambiciosa y representativa de la que podía construirse en el solar que el Patronato Juan de la Cierva les ofrecía. ("Memoria de las actividades del Instituto del Cemento". AHT/ Ol/A/002/001. 1947/1948).

Aunque los planos del "anteproyecto" existentes en el archivo histórico del IETcC no están firmados y tampoco se han encontrado documentos donde se refleje la autoría de los mismos, pero sin embargo no dudamos de que fueron supervisados y dirigidos en lo que al programa de actividades y usos se refiere por Eduardo Torroja, no solo por su gran similitud con el finalmente construido en la actual sede del IETCC, que fue inaugurada en 1953 en otro solar, sino por la firma del Director del Instituto en el informe que acompañó al anteproyecto entregado el 21 de enero de 1950 ante el Patronato Juan de la Cierva.

En cuanto a la tipología arquitectónica, constructiva y estructural de los edificios proyectados, queda patente la no intervención directa de Eduardo Torroja, que esperó a tener un solar adecuado para dejar su más innovadora y racional huella. Probablemente el hecho de que este anteproyecto 
fuera desarrollado con soluciones que no presentan ningún alarde o innovación arquitectónica, es porque solo servían para demostrar lo poco apropiado de sus posibilidades volumétricas para contener la totalidad del programa específico requerido. Por otra parte, aunque pudiéramos pensar en la posibilidad de que el arquitecto Miguel $\mathrm{Fi}$ sac y/o Fernández Villaspín intervinieran de alguna manera en este anteproyecto, dado que en aquellos años proyectaron y construyeron la mayor parte de los centros del $\mathrm{CSIC}^{1}$, parece claro que no, ya que lo lógico es que Eduardo Torroja encargara a técnicos del Instituto su realización. Por ello, lo más probable es que los autores fueran los arquitectos M. Barbero y G. Echegaray, los mismos que posteriormente, y bajo la dirección y supervisión de Eduardo Torro$\mathrm{ja}^{2}$, desarrollaron el proyecto definitivo de la nueva sede del itcc en el solar de Chamartín de la Rosa.

En efecto, a juzgar por los alzados y volumetría de los edificios proyectados en este "anteproyecto", la composición arquitectónica responde en muchos aspectos a los primeros edificios del CSIC, que cuentan con reminiscencias clásicas, más o menos mutiladas en sus simetrías, ejecutadas con basamentos pétreos, con utilización masiva de fábrica de ladrillo y graduación vertical del tamaño de los huecos de fachadas, que disminuyen con la altura del edificio. Un tipo de edificios, que como el de las oficinas centrales del CSIC, proyectado y construido por Miguel Fisac, representaron sin duda un momento de incertidumbre arquitectónica, un camino que como el mismo Fisac reconoció a los pocos días de inaugurar el edificio ${ }^{3}$, era necesario abandonar para buscar nuevas metas (8). Una arquitectura desprovista de la temprana y admirable racionalidad utilizada siempre por Eduardo Torroja, y por algunos de los arquitectos con los que colaboró, entre otros por Arniches y Domínguez, que a principios de la década de los años 30 en la misma "Colina de los Chopos", construyeron el Auditorio de la Residencia de Estudiantes y el Instituto Escuela, contando con la colaboración de Eduardo Torroja, que diseñó la famosa marquesina de hormigón armado del pabeIlón de párvulos (1933-1935). Por ello, por la indudable racionalidad innovadora que siempre presidió la obra de Eduardo Torroja, es extremadamente revelador, no solo la imagen de la arquitectura proyectada, sino también observar que las soluciones estructurales, no solo distan mucho de ser innovadoras, sino que además la propuesta de pórticos de pequeñas luces de vano, cuyos pilares interfieren de manera notable en la diafanidad de las plantas de los edificios, es realmente poco acertada.
Estos aspectos denotan, sin duda, que la finalidad de este "anteproyecto" era demostrar que estos edificios no debían ser construidos jamás. Por ello, Eduardo Torroja no solo no intervino en el diseño estructural de estos edificios, sino que además tampoco pretendió que quienes realizaron el proyecto bajo su supervisión, resolvieran estos aspectos tan claramente importantes. Sin embargo, cuando al fin obtuvo el solar que consideró apropiado para ubicar la nueva sede del itcc, entonces intervino en el proyecto directamente, legándonos nuevas e innovadoras estructuras que hoy forman parte de nuestro más admirado Patrimonio. (Torroja.1958)

En el "anteproyecto" de la solución C (Figura 2) se desarrollaron 4 edificios, que respondían al siguiente programa de usos específicos.

Edificio I: Cuatro plantas sobre rasante más semisótano.

- La planta semisótano alberga los almacenes generales de servicios de todo el edificio, sala de modelos reducidos, cámaras isotérmicas y de observación y vivienda del conserje. En la planta primera se ubica la sala de conferencias y servicios anejos, la sala de ensayos mecánicos, la nave de modelos reducidos (parte en doble altura sobre el semisótano), el servicio de información, conserjería, etc. (Figura 3. IETcc/ Archivo Torroja. 1950).

- La planta segunda estaría dedicada a la secretaría general y servicios anexos: secciones de estudio, información bibliográfica, biblioteca, sala de lectura, publicaciones y servicios administrativos, mientras que en la planta tercera se sitúa el despacho del presidente, la sala de consejos, la dirección, los despachos de investigadores, la sala de coloquios, el gabinete de trabajos especiales, la sección de cálculo, y los servicios anexos. (Figura 4. IETcc/Archivo Torroja. 1950).

- La planta cuarta está dedicada a los laboratorios físico-químicos, archivos, almacenes y servicios anejos a los laboratorios y finalmente en la planta quinta estaría configurada por una gran terraza transitable como cubierta de la mitad del edificio, sala de coloquios, 6 despachos de investigadores, 2 despachos de investigadores y auxiliares, 3 almacenes, escaleras y aseos en ambos extremos de la planta. (Figura 5. IETcc/Archivo Torroja 1950).

- El alzado principal y el esquema de sus instalaciones pueden apreciarse en las Figuras 6 y 7 .
${ }^{1}$ Miguel Fisac realizó, en aqueIlos años, la mayor parte de los proyectos de los edificios del Consejo Superior de Investigaciones Científicas CSIC, así como de algunos de sus centros en Madrid. Entre ellos: 1942 Edificio central del CSIC, 1948-1949 Instituto Nacional de Óptica Daza de Valdés, 1949-1956 Instituto de Microbiología Ramón y Cajal, 1950 Librería del CSIC en la calle Medinaceli, Madrid, España.

2 Todos los planos del Proyecto definitivo de la nueva sede del Instituto fueron firmados por Eduardo Torroja como "propietario autor del encargo" y por M. Barbero y G. Echegaray como arquitectos. Archivo Histórico del IETcc.

3 "Cuando terminé el C.S.I.C., gustó mucho, me hicieron muy buenas críticas Lafuente Ferrari, Camón Aznar...; diciendo que la arquitectura que yo estaba haciendo en los Altos del Hipódromo que era muy importante... Se inauguró con gran pompa, asistió Franco... y me acuerdo que tres o cuatro días después, me fui alli solito, estuve dando vueltas y dije: -Miguel, por aquí no se va a ninguna parte. ¡Para mí, sobro! ¡Aquí hay que buscar otras cosas!-". Miguel Fisac (De Roda 2007). 
3. Anteproyecto no construido. Solución C. Edificio I / Plantas Primera y Semisótano.

IETcc/Archivo Torroja.

4. Anteproyecto no construido. Solución C. Edificio I / Plantas Segunda y Tercera

5. Anteproyecto no construido. Solución C. Edificio I / Plantas Cuarta y Quinta.

IETcc/Archivo Torroja.

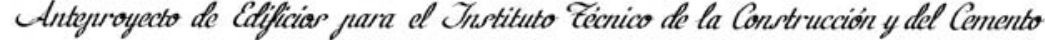
Elficio I - Saboratorion y malas de entutio.

Encala t:2oo

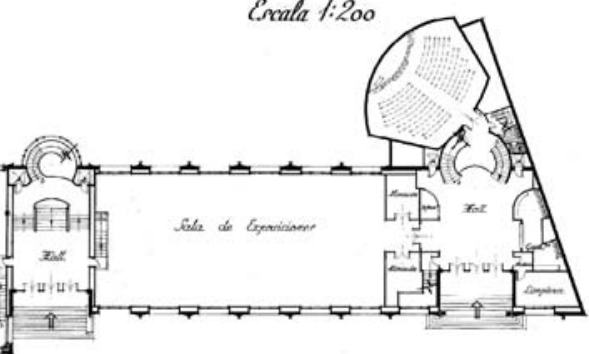

Plantu Primeru

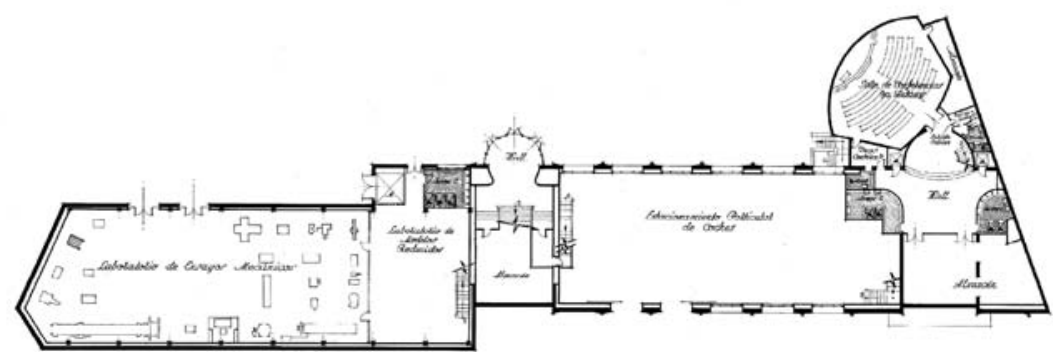

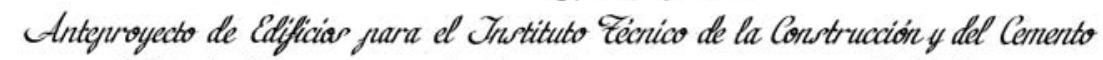
Edaficio I Laboratorias y salas de estudio.

Groala t:200

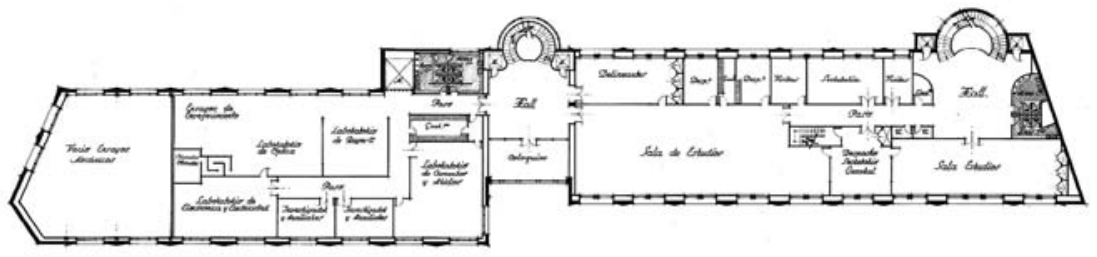

Plantiz Forcerz

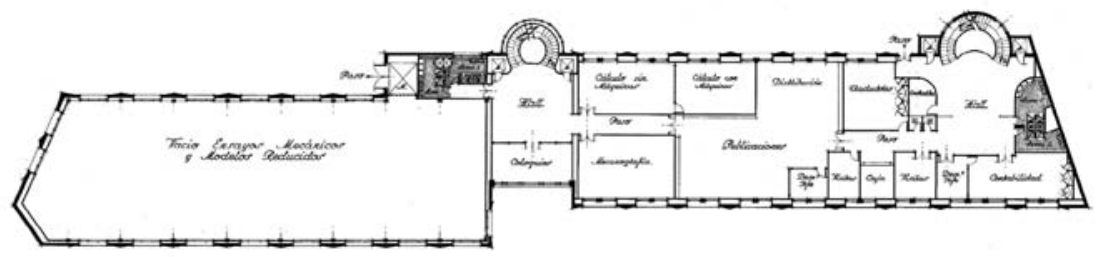

- Intyuroyecto de Éfificiar para el Thstituto Eecnico de la Construcción y del Cemento Eitificio I Laborrtorias y sulus de cutulio.

escolh 1:200

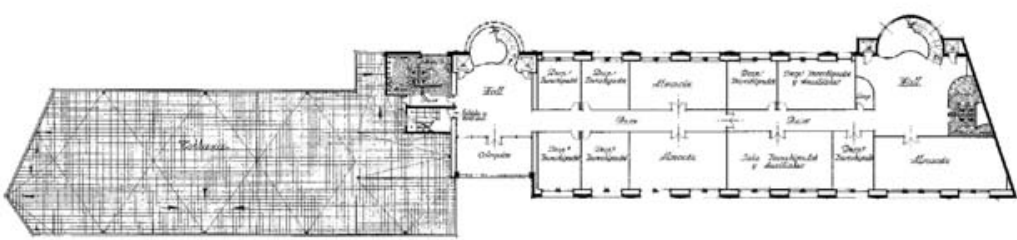

Manta Quinth

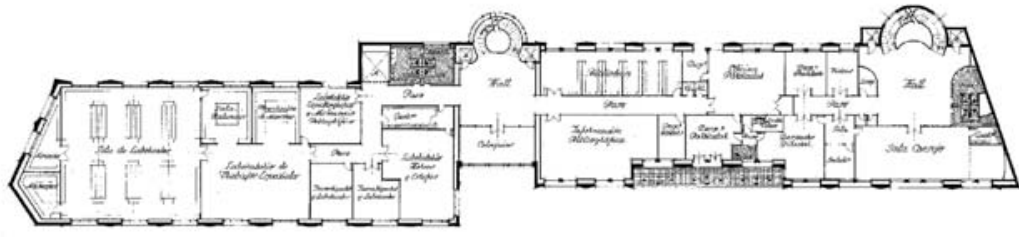

Aanthe Cunoth 


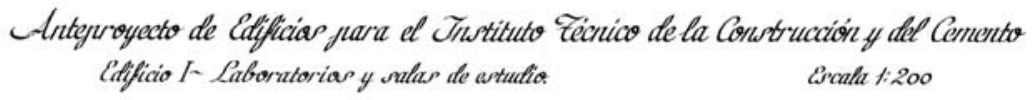

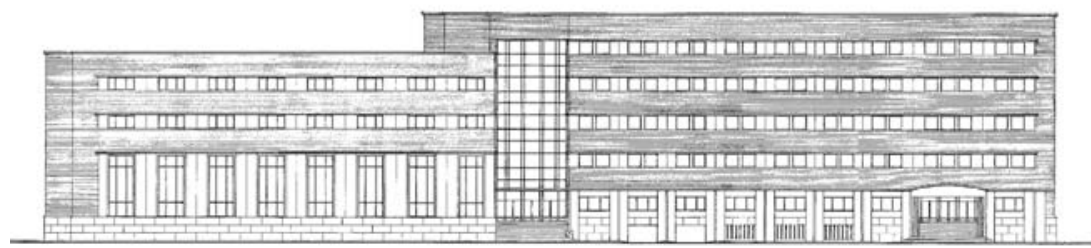

cllado Aringinal

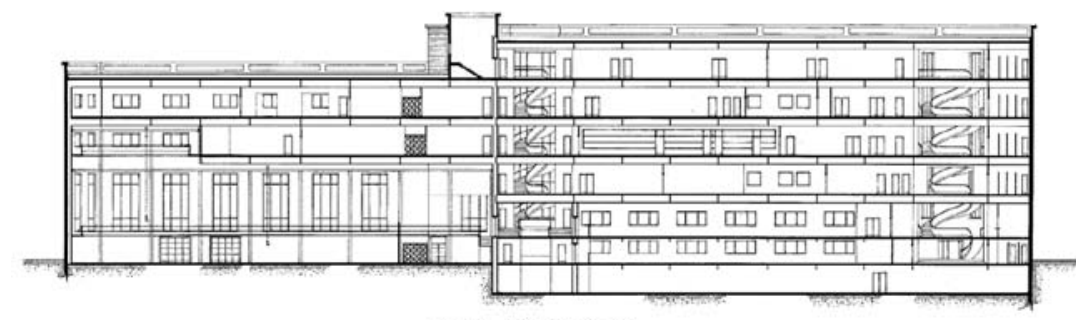

Seccion Longitudinal
6. Anteproyecto no construido. Solución C. Edificio I / Alzado principal y sección.

IETcc/Archivo Torroja.

7. Anteproyecto no construido. Solución C. Edificio I / Esquemas de Instalaciones.

IETcc /Archivo Torroja.

\section{- Integroyedo de Clifficios para el Tnstituto Técnico de la Construcciön y del Cemento
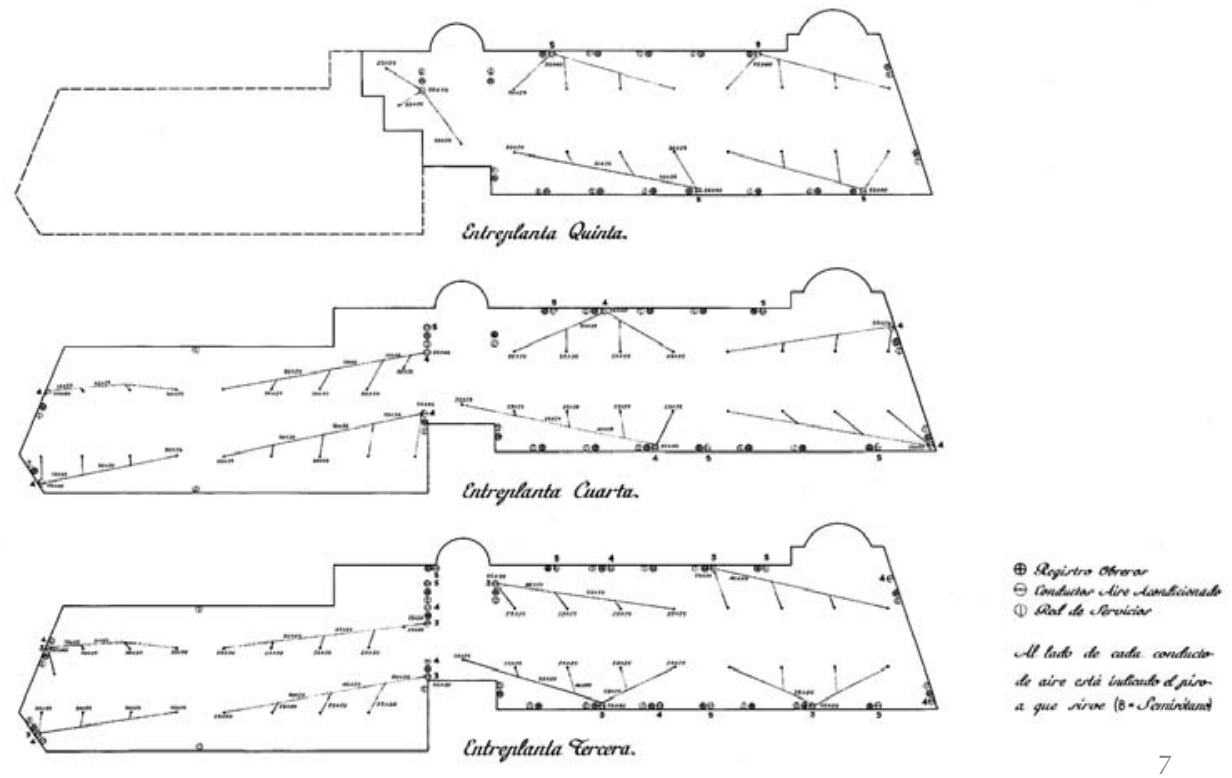

Edificio II (2 plantas sobre rasante + semisótano) (Figura 8):

- Planta Semisótano: Almacenes generales, Lavadero, Planchado, Lencería, Calefacción general para todo el conjunto de edificios.

- Planta Primera: Imprenta y servicios anejos, Almacén general, Residencia de obreros (8 camas), Talleres Mecánicos, Taller de Ajuste, Taller de Carpintería, Servicio de Control y aseos de obreros, Enfermería.

- Planta Segunda: Comedor y Residencia de facultativos (6 camas), Comedor de obreros, Cocina y servicios anejos.
Edificio III: Nave de construcción / fábrica de cemento (2 plantas sobre rasante). En la planta primera se encuentra la nave de construcción (doble altura) y la de fabricación de cemento con sus servicios anejos. En la planta segunda, la nave de construcción, taller de carpintería, etc. (Figura 9)

Edificio IV: Este edificio estaría programado para albergar laboratorios y naves de ensayos en dos plantas sobre rasante y dos semisótanos (Figura 10). En las plantas semisótano se ubicarían los servicios de control de las instalaciones del edificio así como el grupo de machaqueo, trituración, molido y lavado de áridos para estudiar aplicaciones del cemento. 
8. Anteproyecto no construido. Solución C. Edificio II.

9. Anteproyecto no construido. Solución C. Edificio III.

\section{Anteproyecto de Elfificios para el Trustituto Técnico de la Construcción y del Cemento

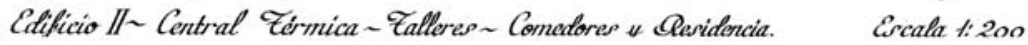

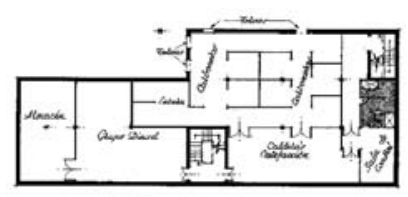

Planta de Sotano
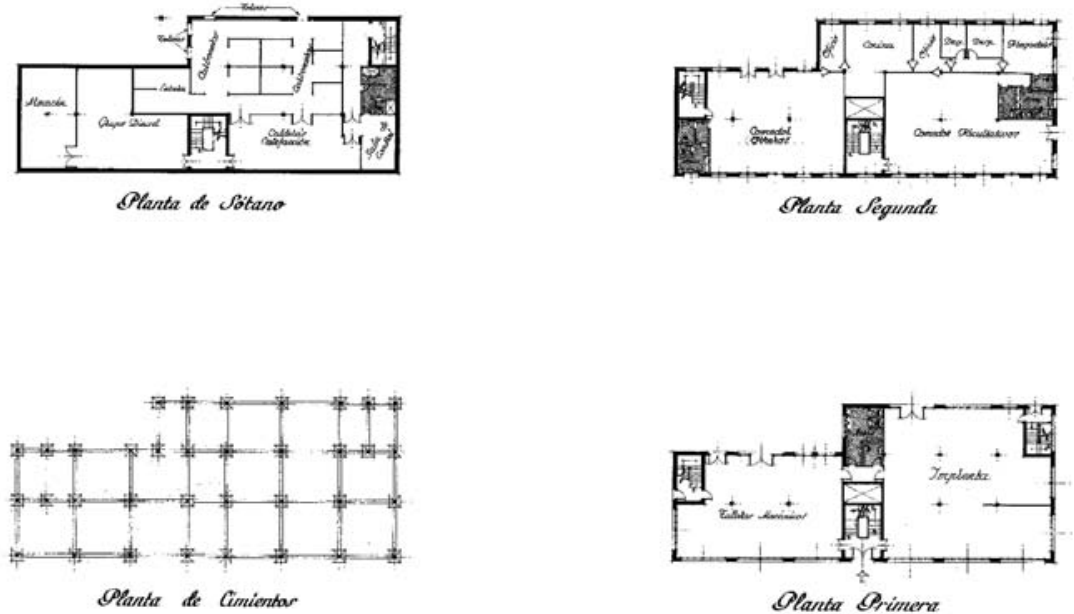

8
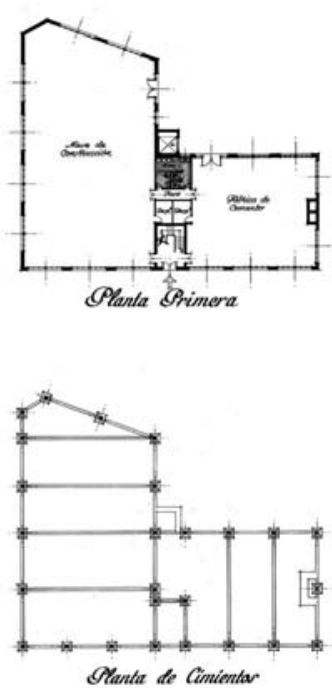

Otanta de Cimientar 9

En las plantas primera y segunda se ubicarían las naves de fabricación de piezas, la sala de precisión, laboratorios para el estudio del cemento, despachos, vestuarios, almacenes, servicios, etc.

Lo realmente importante e innovador del "anteproyecto" que Eduardo Torroja presentó al Patronato Juan de la Cierva en 1950, no es su arquitectura, sino el programa de usos que pretendía establecer en la nueva sede del itcc, en la que de forma clara y rotunda está planteando, por primera vez en España, la creación de un nuevo modelo de centro de investigación de carácter internacional en el que puedan realizarse de forma inseparable, las tres actividades que bajo su punto de vista garantizan el progreso de la sociedad, propiciando y promoviendo la aplicación práctica de los resultados de la investigación científico-tecnológica; Investigación, Difusión y Enseñanza.

Por ello, en la solución C, el programa de actividades no solo recoge todas las necesidades de espacios exclusivos y específicos para la investigación demandados por el Instituto Técnico de la Construcción y del Cemento itcc (laboratorios, naves de ensayos, moldeo, talleres, fábrica de cemento,...) sino que también introduce todos los espacios necesarios para incentivar las relaciones internacionales, la difusión, el debate y la enseñanza. 


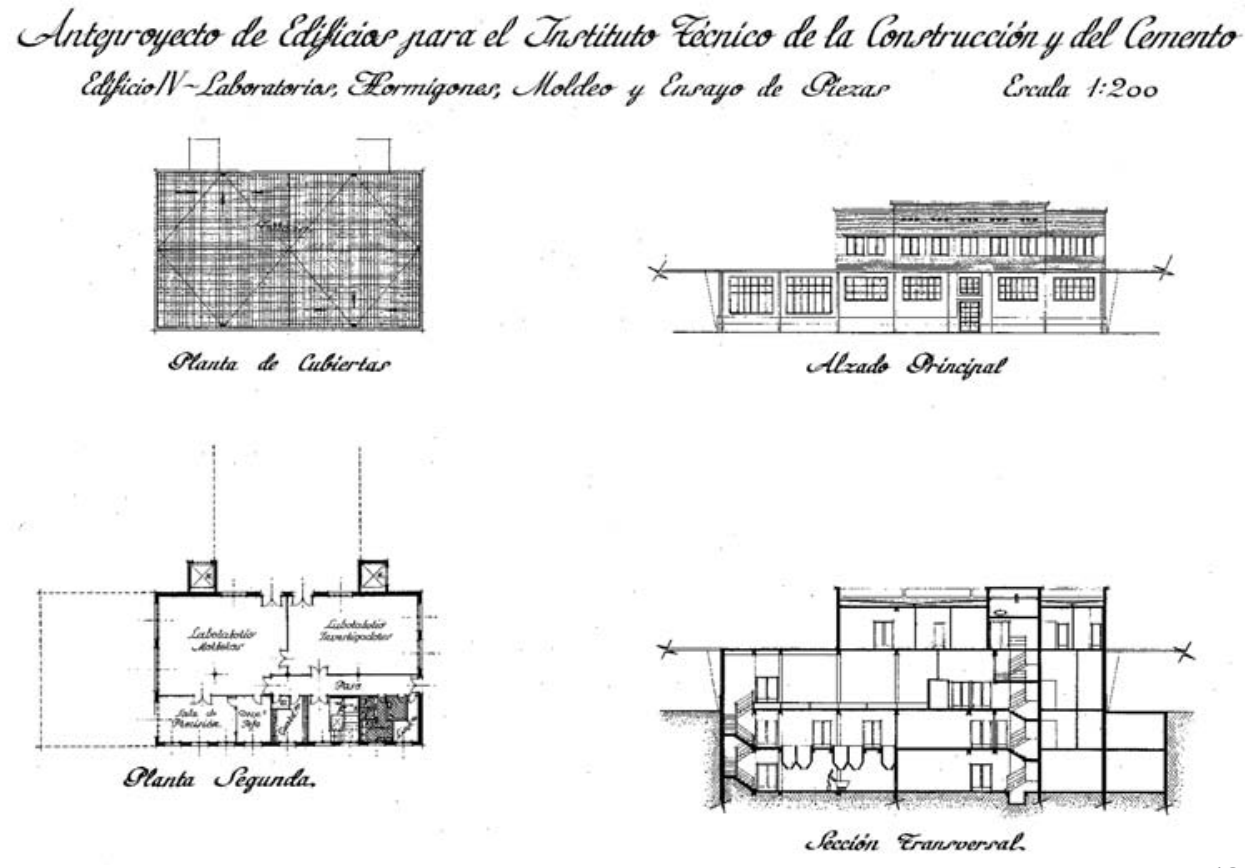

10

El Edificio I, que es el principal y de mayor tamaño, pese a que sus usos se engloban bajo la denominación de "Laboratorios y Salas de Estudios", cuenta con otros muchos usos que nada tienen que ver, y que completan el hábitat que Eduardo Torroja quiere construir para su nueva idea de lo que debe ser un centro de investigación. Por ello, este Edificio I cuenta con dos entradas principales claramente diferenciadas, desde la calle Serrano, una para el personal investigador (técnicos y laborantes) desde la cual se accede a laboratorios, salas de estudios, naves de ensayos, talleres, despachos, ... y otra entrada independiente para visitantes que accede a otros espacios a los cuales destina más de la mitad de la superficie ocupada en planta, en la que ubica un gran salón de actos (doble altura) y una amplia sala de exposiciones. Espacios de debate, difusión y enseñanza, que cobran una enorme importancia en el programa de actividades que Eduardo Torroja incluye con vistas a poder desarrollar cursos, simposios, jornadas, ... no solo de carácter nacional sino también y fundamentalmente de carácter internacional.

Otro aspecto importante en cuanto al programa de usos que incluye Torroja, y que no son específicamente para investigación, son los espacios destinados a "Publicaciones y Distribución", que ubica en la planta segunda de este mismo Edificio I, así como una gran sala de traducción. No hay que olvidar que el itcc, en aquellos momentos, realizaba ya multitud de publicaciones diversas, y que a través de su revista "Informes de la Construcción", servía de crisol científico y técnico de todas las innovaciones que acaecían en el mundo de la construcción civil y arquitectónica.
Durante las décadas de los años 50 y 60, sería la única revista a nivel mundial que llegaría a publicar sus resúmenes en cuatro idiomas diferentes (alemán, inglés, francés e italiano), algo que jamás ha realizado ninguna revista técnico-científica del sector lo que demuestra la enorme relevancia y prestigio que alcanzó el itcc. Por otra parte, el servicio de publicaciones con el que contó finalmente la nueva y definitiva sede del Instituto, no se limitó a la publicación de sus revistas, manuales, normas, ... sino también a traducir y publicar algunos de los más relevantes libros que fueron apareciendo en el sector de la construcción civil y arquitectónica.

Otras de las labores que se realizaban en el Servicio de Documentación y Publicamás relevantes aparecidos en otras revistas de prestigio del sector. No hay que olvidar que, en aquellos años, el porcentaje de técnicos e industriales españoles que hablaban idiomas era muy reducido, razón por la cual les estaba muy limitado el acceso directo al conocimiento de algunas de las más relevantes innovaciones que acaecían a nivel internacional. Eduardo Torroja creó por ello una red internacional de intercambio de información con más de 50 revistas líderes del sector, publicadas en diferentes países. En el Instituto se traducían dichos artículos y se publicaban en la revista Informes de la Construcción. Entre las revistas que colaboraron con el Instituto cediendo los artículos que les eran solicitados, están: Annales de L'Institut Technique du Batiment, Architect and Engineer, Architectural Design, Architectural Forum, Batir, Bauen und Wohnen, Bauwelt, Beton und ciones era la traducción de los artículos 
Stahlbetonbau, British Engineering, British Engineering Export Journal, Civil Engineers (American Society of Civil Engineers), Civil Engineering and Public Works Review, Concrete, Concrete and Constructional Engineering, Construction Methods and Equipement, Der Bau, Der Bauingenieur, Detsche Bauzeitung, Domus, Edilizia Moderna, Engineering, Engineering News Record, Excavating Engineering, Giornale del Genio Civile, Heating and Ventilating, House and Home, Il Cemento, Journal of the American Concrete Institute, Journal of the Royal Institute of British Architects, La Techique des Travaux, La Technique Moderne - Construction, L'Architecture D'Aujourd Hui, Le Genie Civil, Leichtbeton in Schweden, L'Equipement Mecanique, L'Ingegnere, L'Ossature Metallique, Materiaux de Construction, Ospedali, Progressive Architecture, Public Works, Public Roads, Techniques et Architecture, The Architect, Travaux, Schweizerische Bauzeitung, Structura, Travaux, Western Construction News (9).

El "anteproyecto" denominado como solución C, además de incluir una amplia biblioteca, que sitúa en la planta cuarta del Edificio I, incluye también una sala de "Información Bibliográfica". Este es otro de los servicios que considera de enorme interés y que ya había creado en el itc, con el fin de ayudar a técnicos y especialistas, no solo del propio instituto, sino fundamentalmente externos a él. Un nuevo modelo de facilitar el estudio y aprendizaje de cuantos temas de interés surgían en el sector de la construcción, facilitando ayuda y difusión, no solo de sus propias publicaciones, sino también de todo lo que de forma relevante estaba impulsando el progreso a nivel internacional.

Otro aspecto a resaltar de este "anteproyecto" es el hecho de que en la misma planta cuarta del Edificio I, donde se ubica el despacho del director del itcc, se ubica también una sala denominada "oficina particular". Se trata de la oficina particular del propio Eduardo Torroja que siempre compatibilizó su trabajo profesional de ingeniero proyectista con el de director del Laboratorio Central (desde 1940), director del itcc y catedrático de la Escuela Superior de Ingenieros de Caminos, Canales y Puertos de la Universidad Politécnica de Madrid. Sin duda su experiencia profesional le permitió conocer el adecuado y específico camino que era necesario trazar para encauzar debidamente las líneas de investigación en el campo de la construcción, no despilfarrando energías y medios en caminos inadecuados o poco productivos. Su actividad docente le sensibilizó y capacitó para poder contribuir de forma audaz en la formación, ya no de uni- versitarios sino también de técnicos (arquitectos e ingenieros), industriales, constructores, laborantes, etc. A todos ellos destinó su "internacional escuela", que finalmente consiguió crear en la nueva y actual sede del itcc, hoy IETcc "Instituto de Ciencias de la Construcción Eduardo Torroja", situada en Chamartín de la Rosa.

En cuanto al programa de usos y espacios destinados a la investigación -objetivo fundamental del centro-, antes de establecerlo de forma pormenoriza y específica, la Dirección del Instituto junto con sus investigadores más destacados, analizó gran parte de los edificios, centros, institutos y laboratorios, que a nivel mundial se habían ya creado. Centros con los que estableció una estrecha relación, interviniendo en gran medida en el destino internacional de los planteamientos básicos comunes, que en aquellos momentos estaban centrados fundamentalmente en la necesaria evolución y redacción de normas del hormigón armado y pretensado, así como en el desarrollo de esa nueva Arquitectura de formas libres: las estructuras laminares de la Modernidad. La investigación planteada abarcó también todas aquellas parcelas que el estado del mercado y de la industria demandaban, como la racionalización de sistemas constructivos tradicionales, la prefabricación, etc... Pero es importante resaltar nuevamente, que toda innovación alcanzada tenía como última e imprescindible fase, su aplicación práctica, ya que el objetivo final era poner la Ciencia y la Tecnología al servicio del progreso de la sociedad. Frente a este objetivo, lo que diferenció a Eduardo Torroja de todos los que compartían y comparten esta idea, es que él no solo manifestó esta relevante creencia, a lo largo de toda su vida, en escritos (1012), simposios y conferencias impartidas en diferentes países (13), sino que fue el único capaz de llevarla a cabo creando un nuevo Instituto, el itcc, en el que fundó su "internacional escuela" de investigación aplicada, uniendo en ella, de forma patente, el camino de la Ciencia y la Técnica al servicio del progreso de la sociedad (14).

Una vez conocidos los planteamientos existentes en otros países y las necesidades de la investigación del sector, Eduardo Torroja perfila el programa de necesidades de su nuevo Instituto, aportado estos datos al Patronato Juan de la Cierva en defensa de su imperiosa necesidad de "construir un nuevo y adecuado hábitat" para su Instituto. Pero además, desde su clara audacia y vocación de líder, difunde, a través de la revista "Informes de la Construcción" la importancia que tiene el hecho de que España cuente con un centro de investigación competente a nivel internacional, centrado en las necesidades 
específicas del sector, de las peculiares características de los recursos naturales, así como de la industria española en aquellos momentos. A tal efecto dedica un número monográfico de esta revista, al análisis de algunos de los laboratorios de investigación de mayor prestigio, escribiendo personalmente una introducción en la que expone la imperiosa necesidad de que los planteamientos de la investigación del sector de la construcción evolucionen, ya no puede estar destinada exclusivamente al ensayo de materiales, sino que ha de abrirse a la investigación de los múltiples y variados temas que demanda el confort de las construcciones civiles y arquitectónicas (15). El análisis de los laboratorios y centros de investigación que Eduardo Torroja incluye en el número 36 de la revista "Informes de la Construcción" fueron escritos por sus propios directores, otro aspecto a destacar y que Eduardo Torroja siempre tuvo presente, la importancia de que quienes relatan una determinada historia sean precisamente quienes los que la están construyendo. Se incluyeron un total de 32 laboratorios y/o centros de investigación del sector de la construcción, pertenecientes a 17 países diferentes (Alemania, Australia, Bélgica, Canadá, Dinamarca, España, Estados Unidos, Finlandia, Francia, Holanda, India, Inglaterra, Italia, Noruega, Portugal, Suecia, Suiza). A través de estos textos se pone de manifiesto, el estado de la investigación internacional en el sector de la construcción, justo en el preciso momento en los que él establece el nuevo y ambicioso programa de usos de la nueva sede del itcc. Un programa de Instituto de investigación que demandaba un nuevo "hábitat" y cuya posterior construcción le permitió ponerse a la cabeza de todos ellos, liderando este campo de investigación a nivel internacional, en el que incluyó una fuerte dosis de enseñanza y difusión de los avances alcanzados.

La estrategia de Eduardo Torroja para conseguir construir un adecuado "hábitat" para su nuevo Instituto fue audaz, minuciosa, rotun- da y clara. Tenía que demostrar al Patronato Juan de la Cierva, por un lado, que el programa que él proponía era el adecuado, y por otro lado, que el solar que le ofrecían no servía para acoger dicho proyecto. Respaldó su ambicioso programa con el extenso y específico análisis realizado sobre el qué y el cómo se estaba investigado en el resto del mundo, y demostró lo inadecuado del solar que le ofrecían, desarrollando un "anteproyecto" a nivel de proyecto de ejecución de cuatro edificios, que tal y como hemos visto, pone de manifiesto que no debían llegar a ser construido jamás.

Pero tras este enorme esfuerzo, a Eduardo Torroja todavía le quedaban otros dos aspectos fundamentales que superar para poder construir su nuevo Instituto. El primero encontrar en Madrid un solar adecuado a su programa, y el segundo y último, aunque no menos importante, conseguir el dinero para pagarlo, ya que era muy improbable que el Patronato Juan de la Cierva (CSIC) sufragara dicho coste. Por ello, y de forma paralela al desarrollo del "anteproyecto" y análisis de los institutos y centros de investigación existentes en diferentes países, Eduardo Torroja analizó todos los solares que en aquellos momentos estaban en venta en Madrid y sus alrededores, preparando un informe detallado de los mismos para presentárselo al Patronato Juan de la Cierva.

\section{ELECCIÓN DEL SOLAR DEFINITIVO (1950)}

En efecto, transcurridos tan solo 5 meses (20 junio 1950) de haber presentado al Patronato Juan de la Cierva las tres soluciones A, B y C anteriormente comentadas, Eduardo Torroja, como director del itcc, propuso al Patronato Juan de la Cierva (CSIC) la compra de otro solar para la construcción de su nueva sede. Se trataba de un terreno de aproximadamente 5 hectáreas de superficie, propiedad de la Compañía de Jesús, situado en Chamartín de la Rosa, muy cerca de la calle Arturo Soria (Figura 11).

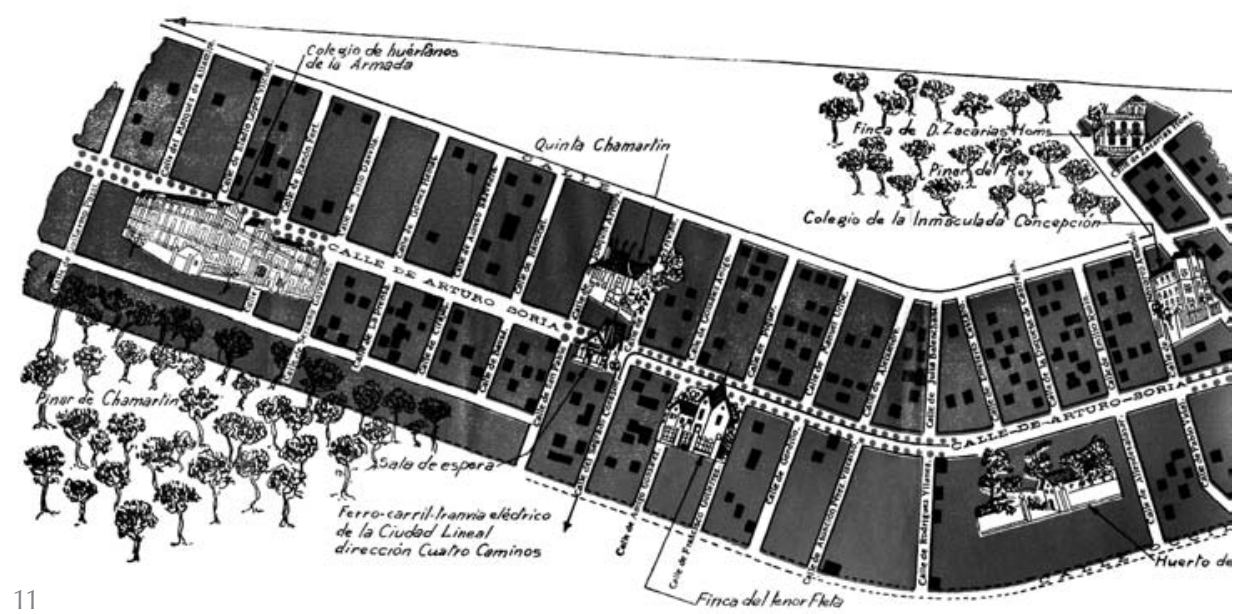

11. Situación del solar "Pinar de Chamartín". Plano de la Ciudad Lineal de Arturo Soria. Guía de la Ciudad Linealoctubre 1930) 
12. Planta general de la nueva sede del itcc.
El itcc acompañó a esta propuesta de un estudio sobre otros 13 solares que había analizado previamente, en busca de un suelo que cumpliera todos los requisitos que consideraba fundamentales: gran extensión, cercanía a Madrid, entorno apropiado y coste moderado. Todos los solares seleccionados de los que se encontraban en venta en Madrid, presentaban algunos inconvenientes importantes. Ninguno de ellos reunía todos los requisitos que Eduardo Torroja consideraba fundamentales para construir la nueva y definitiva sede de su Instituto. La mayor parte de ellos estaban muy alejados del centro de la ciudad, en general mal comunicados y en algunos casos se encontraban en un entorno muy degradado o de marcado uso industrial. Aspecto, este último, que Eduardo Torroja consideraba no apropiado para su centro, ya que pretendía convertirlo en atractiva sede de reuniones de debate internacional. Estos estaban ubicados en las zonas de: la Estación de Santa Catalina, la carretera de Fuencarral en Montecarmelo, la carretera de Valencia, la carretera de Andalucía, al final de la calle Méndez Álvaro, o en el camino de Vicálvaro junto al arroyo de Abroñigal. Su precio de venta oscilaba entre 1,25 y 5,87 pesetas el pie cuadrado, mientras que los solares ubicados en la trama urbana de Madrid tenían un precio medio de 40 pesetas pie cuadrado y que por otra parte, contaban con superficies muy escasas para poder desarrollar el amplio programa que Eduardo Torroja tenía previsto para la nueva sede del Instituto. (Archivo Torroja - D11(1950)

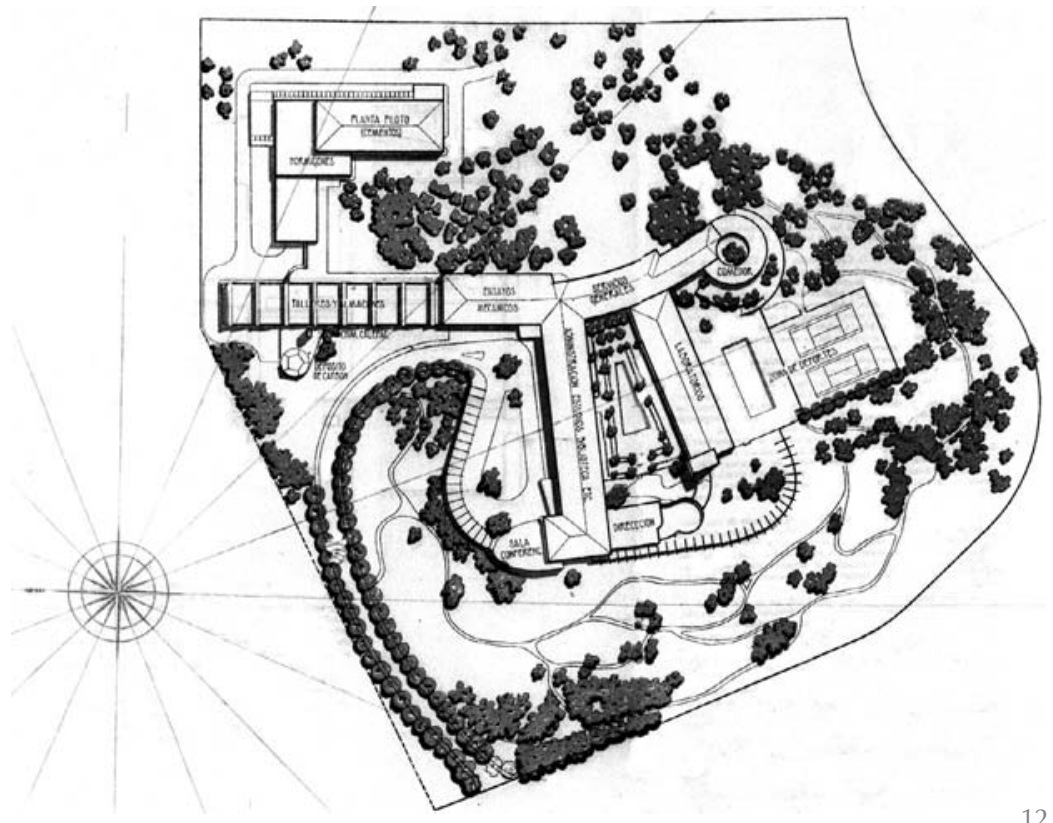

12

Dentro de los terrenos en venta, existía un solar ubicado en Chamartín de la Rosa -"Pinar de Chamartín" (Costillares)-, muy cercano a la calle Arturo Soria y que cumplía todos los requisitos que Eduardo Torroja buscaba. El solar estaba entre la futura avenida del Arroyo del Abroñigal y los edificios que ocupaba la Marina en la calle Arturo Soria, ubicada dentro de una zona contemplada en la nueva ordenación como de uso de "edificios de investigación", delimitada entre dos grandes zonas verdes, una pública y otra privada. El solar contaba con una extensión de casi 5 hectáreas, hecho que permitía desarrollar el programa de actividades en edificios de una sola planta, ó máximo dos, conservando gran parte de la frondosa vegetación existente. Además, aunque por aquel entonces el solar estaba algo alejado del centro de la ciudad, su cercanía a la caIle Arturo Soria, la famosa "Ciudad Lineal" dotada de tranvía que facilitaría el transporte de acceso a la nueva sede del itcc y que garantizaba la futura consolidación y desarrollo del tejido urbano en sus bordes, además este tranvía, desde 1949 había pasado a ser propiedad del ayuntamiento de Madrid (16) (Figura12).

El precio del solar en venta en Chamartín era de cinco millones doscientas mil pesetas (8 pesetas pie cuadrado), ligeramente superior al del resto de solares analizados a las afueras de Madrid y que estaban mucho más alejados y peor comunicados que este. Pero su precio tenía un valor muy inferior al de los solares analizados en el centro de Madrid, que además tenían una escasa superficie para el adecuado desarroIlo del programa de actividades del itcc, al igual que ocurría con el solar propiedad del propio Patronato Juan de la Cierva, situado entre las calles Serrano, Gustavo Fernández Balbuena y Joaquín Costa, que tan celosamente habían analizado desarrollando en el anteproyecto descrito, para demostrar que era inadecuado e insuficiente. Sin duda, Eduardo Torroja dedicó un especial esfuerzo para conseguir que la nueva y definitiva sede del Instituto fuese la adecuada para poder desarrollar su idea sobre lo que debería ser la investigación en el campo de la construcción. Por ello, la petición que presenta al Patronato Juan de la Cierva para la compra del solar de Chamartín de la Rosa, fue acompañada también de la petición del permiso para que fuera el propio itcc quien comprara dicho solar a cargo de los fondos que ha obtenido de la industria del cemento para tal fin. De esta manera, era imposible no obtener el necesario permiso del Patronato, ya que además de presentarse como la solución idónea, el Patronato quedaba libre de tener que realizar ninguna inversión de sus propios presupuestos, contando además con mayor espacio libre en su solar de la caIle Serrano, para poder ubicar en él otro Instituto de los muchos que de él dependían. 
Tal y como era de esperar después de tan audaz planteamiento, Eduardo Torroja obtuvo el permiso del Patronato Juan de la Cierva para comprar el solar de Chamartín de la Rosa con los fondos que el itcc había obtenido de la venta de sus publicaciones, y fundamentalmente de las aportaciones realizadas por industria del cemento ${ }^{4}$. Un hecho que como ya hemos comentado, y la Historia ha constatado, cambió el destino de la investigación española en el campo de la construcción civil y arquitectónica, ya que Eduardo Torroja pudo construir un adecuado hábitat para desarrollar plenamente su nueva, ambiciosa y revolucionaria idea.

\section{NUEVA SEDE: PROYECTO Y CONSTRUCCIÓN (1951-1953)}

Transcurridos casi dos años desde que Eduardo Torroja iniciara su audaz estrategia para conseguir un adecuado hábitat para la nueva sede del itcc, en el año 1951 fue adquirido el citado solar ubicado en Chamartín de la Rosa, y a los pocos meses, los directivos del Instituto presentaron al Patronato Juan de la Cierva el nuevo y definitivo anteproyecto del cual hay que destacar un hecho suficientemente significativo: el caso de que Eduardo Torroja firmara los planos del proyecto de la nueva sede del Instituto Técnico de la Construcción y del Cemento como "propietario", dejando así patente su intervención como máximo director y supervisor de cuanto se proyectó.

Tal y como ya se ha referido, se trataba de un ambicioso proyecto que vendría a dotar al Instituto del suficiente y adecuado espacio para albergar todas las instalaciones necesarias para el desarrollo de sus múltiples funciones, convirtiéndolo en buque insignia de la investigación a nivel internacional ${ }^{5}$.

El solar finalmente elegido, era denominado "El Bosque" y estaba situado en los pinares de Nuestra Señora del Recuerdo, en Chamartín de la Rosa. Contaba con un fuerte desnivel natural hacia la zona de poniente, y una superficie aproximada de $55.000 \mathrm{~m}^{2}$.

En el proyecto presentado al Patronato se describía el plan de necesidades, así como el anteproyecto de las edificaciones que deberían realizarse. Los arquitectos encargados de realizar el proyecto, bajo la dirección de Torroja, fueron Gonzalo Echegaray y Mariano Barbero. Previo al diseño y organización espacial de los diferentes espacios requeridos, Eduardo Torroja manifestó la necesidad de que la nueva sede del Instituto debería ser capaz de adaptarse en el futuro a las específicas demandas del progreso.

El programa de usos que Eduardo Torroja estableció, superaba las expectativas de

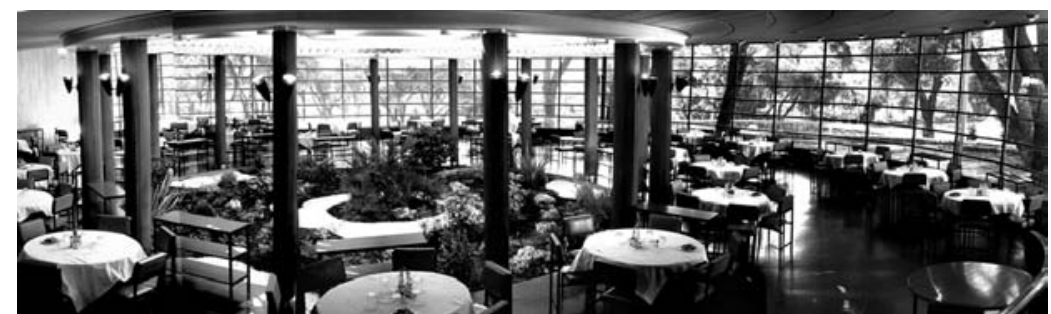

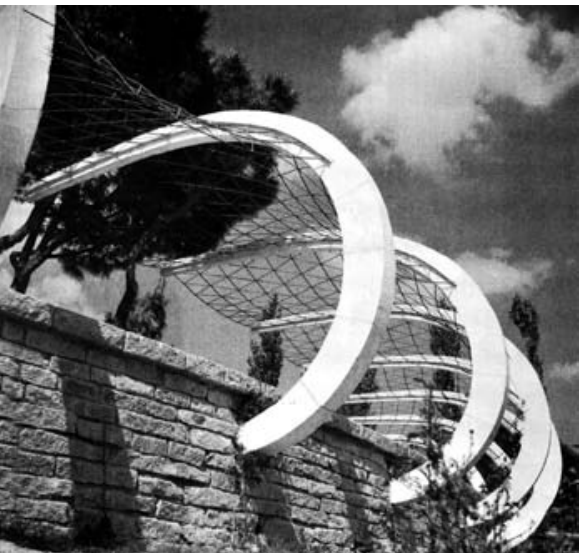

todos los centros de investigación que existían a nivel mundial, e incluso del programa que él mismo recogió en el "anteproyecto" no construido, ya que la gran superficie del solar y el bosque natural que contenía, le permitían integrar en el programa atractivos lugares exteriores de esparcimiento y encuentro. Este anteproyecto contemplaba tres tipos de usos claramente diferenciados; los relacionados con el trabajo de oficina y laboratorio, los lugares de reunión, debate internacional y difusión de conocimientos, y los ligados a la realización de grandes ensayos experimentales y talleres.

Pese a los múltiples aspectos de relevante interés existentes en la organización espacial del conjunto de sus construcciones sin duda, lo más destacable de la nueva sede del Instituto fueron las aportaciones singulares realizadas. Eduardo Torroja convirtió la construcción de la nueva sede del itcc en un verdadero taller experimental, en el que bajo su directa dirección se llevaron a cabo multitud de elementos prefabricados, que ejecutados a pie de obra, optimizaron el tiempo y el coste de la construcción, coincidiendo con las experiencias que por aquellos años estaba realizando también Pier Luigi Nervi en Italia.

Pero este importante aspecto del planteamiento del proyecto desde su inicio -basado en la necesidad de experimentar e investigar para poder innovar- se vio potenciado de manera especial, por la aportación de las innovadoras estructuras y espacios arquitectónicos proyectados por Eduardo Torroja en las más singulares edificaciones del conjunto de esta nueva sede del Instituto; el Comedor circular, el silo de
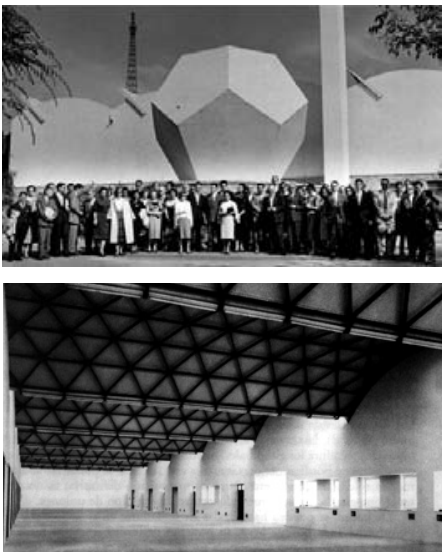

13. Imágenes de la nueva sede del itcc: Comedor, Costillas, Dodecaedro y Talleres.

${ }^{4}$ (AHT/EC/A/010/001. "Documentación administrativa relativa a la adquisición de los terrenos, obras, acometidas agua y luz del edificio en Costillares, para el futuro Instituto" Créditos Plan Marshall. 269 documentos. 1950-1958).

${ }^{5}$ AHT/EC/DD/036/001 "Proyecto de la nueva sede del Instituto Técnico de la Construcción y del Cemento sito en el Pinar de Chamartín. Madrid". Arquitectos: M. Barbero Rebolledo y G. Echegaray Comba. Propietario: Eduardo Torroja. Memoria, Pliego de Condiciones, Presupuesto y 36 Planos en papel azográfico, fechados y firmados por el propietario E. Torroja y los dos arquitectos. Sin sellar. 1951-1953. 
carbón con forma de Dodecaedro, la cubierta Laminar triangulada de los talleres y naves de ensayos, la sustentación de la entreplanta sobre el hall principal de acceso, y la Pérgola de borde (Figura 13). Es significativo que todas estas construcciones fueran posteriormente seleccionadas por el propio Eduardo Torroja, de entre todas sus obras, para ser recogidas en su libro titulado "las estructuras de Eduardo Torroja", publicado en 1958 por F.W. Doge Coorporation, New York. (Torroja 1958) En este libro aparecen tan solo 30 de las estructuras proyectadas por Eduardo Torroja, y en el prólogo comenta:

"...no se mencionan aquí muchas de mis obras, pero creo que aquellas que se han incluido ejemplifican lo que perseguía, y lo que finalmente conseguí." Eduardo Torroja

Estas singulares obras que Eduardo Torroja proyectó y construyó en la nueva sede del itcc, han sido también ampliamente difundidas y analizadas, no solo por el propio Eduardo Torroja, sino también por múltiples profesionales de la arquitectura y la ingeniería. Sin embargo, dado que durante los trabajos de clasificación de documentos del archivo del itcc, han aparecido algunos planos del proyecto de estas singulares estructuras, estamos preparando la publicación de un libro, que tal y como ya hemos referido, bajo el título "Archivo Eduardo Torroja. De la Investigación en Construcción y de su innovador Hábitat" difundirá esta inédita documentación, ampliando el conocimiento específico del proyecto de la nueva sede del Instituto, así como el análisis de las investigaciones y actividades de difusión y enseñanzas realizadas.

\section{CONCLUSIÓN}

La documentación inédita localizada, permite conocer y difundir la audaz estrategia seguida por Eduardo Torroja, para defender su revolucionaria idea de cómo debía ser el espacio arquitectónico adecuado a su modelo de investigación. A la defensa de esta idea, Eduardo Torroja dedicó cinco años (19491953), consiguiendo finalmente, construir en Madrid la nueva y actual sede de su Instituto, el más innovador hábitat de la investigación del sector, que la Modernidad construyó en toda su Historia. Sin duda, Torroja era consciente de que sin este nuevo y específico hábitat, la labor de investigación del itcc no hubiera podido alcanzar la relevancia internacional obtenida.

\section{BIBLIOGRAFÍA}

(1) Nadal, J.: El Instituto de la Construcción y del Cemento. Informes de la Construcción, $N^{\circ} 55,1953$.

(2) Barbero, M. y Echegaray, G.: El Instituto es Así / Composición Arquitectónica. Informes de la Construcción, No 56, 1953.

(3) Eymar, J. M.: El Instituto es Así / Prefabricados. Informes de la Construcción, № 57, 1954.

(4) Laorden, J.: El Instituto es Así / Instalaciones del Edificio de Costillares. Informes de la Construcción, № 58, 1954.

(5) Arredondo; F.: El Instituto es Así / Organización de Obra. Informes de la Construcción, $\mathrm{N}^{\circ} 59,1954$

(6) Oñate Gil, V.: El Instituto es Así / Iluminación artificial. Informes de la Construcción, $\mathrm{N}^{\mathrm{o}} 61,1954$.

(7) Nadal, J.: Costillares, su organización y funcionamiento. Informes de la Construcción, $N^{\circ} 62,1954$

(8) De Roda Lafuma, P.: Miguel Fisac. Apuntes y viajes. Madrid, Ed. Escirptum, 2007.

(9) Cassinello, P.: El espíritu impreso de una idea / The spirit of an idea in print. Libro catálogo exposición conmemorativa de los 60 años de la revista Informes de la Construcción IETcC. Madrid, CSIC-AMIET. 2008

(10) Torroja, E.: Introducción sobre la investigación en el campo de la construcción. Informes de la Construcción, № 36, 1951.

(11) Torroja, E.: Laboratorios. Revista de Obras Públicas, № 101, tomo 2857, 1953.

(12) Torroja, E.: Razón y Ser de los tipos estructurales. CSIC. 1957.

(13) Torroja, E.: General report on safety. IV Congress of Laboratories. Cambridge (1952).

(14) Op. cit. Cassinello, P.: El espíritu impreso de una idea...

(15) Torroja, E.: Informes de la Construcción, No 36, 1951.

(16) Soria, A.: Guía de la ciudad lineal, plano anexo. Madrid, 1930. 